\title{
COMMUNITY HEALTH CENTERS AND RACIAL/ETHNIC DISPARITIES IN HEALTHY LIFE
}

\author{
Leiyu Shi, Jerrilynn Regan, Robert M. Politzer, \\ and Jue Luo
}

\begin{abstract}
This study examined disparities in health status among individuals of different racial and ethnic groups cared for by the nation's community health centers (CHCs) and compared these results with the findings for individuals using non-CHC sites as their usual source of care. The sample consisted of $\mathrm{CHC}$ users from the 1994 CHC User Survey and non-CHC users from the 1994 National Health Interview Survey. Bivariate comparisons were made between individuals' race/ethnicity and their experience of healthy life, an integrated measure that incorporates both activity limitation and self-perceived health status. Multiple regressions were followed to examine the independent association of race/ethnicity with healthy life experience for both $\mathrm{CHC}$ and non-CHC users while controlling for sociodemographic correlates of health. Among CHC users, racial and ethnic minorities did not have worse health than whites, but among non-CHC users there were significant racial and ethnic disparities: whites experienced significantly healthier life than both blacks and non-white Hispanics. These findings persisted after controlling for sociodemographic correlates of health. The results indicate that while racial/ethnic disparities in health persist nationally, these disparities do not exist within CHCs, safety-net providers with an explicit mission to serve vulnerable populations.
\end{abstract}

Despite continuous increases in spending on U.S. health and social welfare programs, racial/ethnic disparities persist in access to care and in health status, morbidity, and mortality, with minorities consistently lagging behind whites in almost all indicators (1-15). The concept of "minorities" is a relative one, but one that is used around the world to designate populations that are racially or ethnically different from the majority. The designation of a group as a minority often suggests that the members of the group are relatively poor and powerless and

International Journal of Health Services, Volume 31, Number 3, Pages 567-582, 2001

2001, Baywood Publishing Co., Inc. 


\section{8 / Shi et al.}

socially marginalized (16). The rapid growth of the minority population in the United States coupled with the persistent and widening disparities in the prevalence of health problems across racial/ethnic groups have prompted policymakers to focus national attention on reducing and eliminating these health disparities. In February 1998, President Clinton committed the nation to eliminating health disparities across racial/ethnic groups in six areas: infant mortality, cancer screening, cardiovascular disease, diabetes, HIV/AIDS, and childhood/adult immunization. Healthy People 2010 has also formally set the national goal of eliminating health disparities by the year 2010 (17).

Studies have demonstrated that minorities with a regular source of care are more likely to experience improved access, higher quality of care, and better health outcomes than those without a regular source of care (18-24). About half of vulnerable people seek care at mainstream sites such as physicians' offices $(25,26)$. However, community health centers $(\mathrm{CHCs})$ and hospital outpatient departments, the nation's core safety-net providers, serve predominantly vulnerable populations. These latter systems are ideal settings to examine the extent to which racial/ethnic disparities exist even among those with a regular source of care. Several studies have determined that racial/ethnic disparities in access to care are reduced or even eliminated in $\mathrm{CHCs}$ when compared with care received by non-CHC users $(27,28)$. However, little is known about the impact of these disparities on health outcomes (20).

The purpose of this study was to examine the disparity in health status among individuals of different racial and ethnic groups cared for by the nation's CHCs and to compare these results with the findings for individuals with non-CHC sites as their usual source of care. Community health centers have served as a primary care safety net for the nation's medically vulnerable populations in both inner-city and rural areas since their inception in the 1960s $(29,30)$. They provide comprehensive, coordinated, and integrated health care, including primary and preventive care services, within a single institutional setting for persons residing in their service areas. Their central mission is to increase access to community-based primary health care services and improve the health status of medically vulnerable populations. In 1998, health centers consisted of nearly 700 organizations delivering services at more than 3,000 sites to an estimated nine million people, among whom about 40 percent were uninsured, 65 percent were members of racial/ethnic minority groups, 6 percent were homeless, 33 percent were covered by Medicaid, and 85 percent had low incomes (27).

Results of this study will help identify health care settings more likely to be associated with racial/ethnic disparities in health. Such information is critical to policymakers intent on reducing and eliminating health disparities. If CHCs are more likely to be associated with less disparity, then efforts can be made to sustain and expand CHCs in an attempt to reduce health disparities. Alternatively, attempts can be made to improve primary care practice in other (mainstream) health care settings with a focus on comprehensive, coordinated, 
integrated, and racially and culturally sensitive health care to the nation's poor and underserved.

\section{METHODS}

Data

Data for this study came from two sources: the 1994 CHC User Survey (User Survey) and the 1994 National Health Interview Survey (NHIS). The User Survey is a study of $\mathrm{CHC}$ medical care users randomly selected from a nationally representative sample of $48 \mathrm{CHCs}$ (31). A total of 1,932 randomly selected CHC patients were interviewed about their health status, use of health services, satisfaction with care, access to care, and demographic characteristics. The overall purpose of the User Survey was to obtain, for the first time, nationally representative data about users of CHCs and the services provided to them. These data provide policymakers with a better understanding of who is being served and the extent to which the CHCs are serving as the safety net for vulnerable populations. The NHIS, conducted since 1957 by the National Center for Health Statistics, is an annual household survey of the civilian noninstitutionalized U.S. population. A multistage probability design is used in sample selection so that information collected on the health and sociodemographic characteristics of the sample can be generalized to the U.S. population. The 1994 NHIS data were used to construct a comparison group from the general population. Analyses in this study describe and compare variations among $\mathrm{CHC}$ users and non-CHC users as drawn from the general population.

\section{Measures}

We identified measures within the User Survey and NHIS that denote race/ ethnicity, health status, usual source of care, and socioeconomic covariates associated with health.

Race/Ethnicity. Data on race have been collected routinely since the first decennial census in 1790 (32). Even though the U.S. population is heterogeneous, there are only four generally recognized minority groups. The classification of race/ethnicity used in this analysis is consistent with the Office of Management and Budget's published Directive 15, "Race and Ethnic Standards for Federal Statistics and Administrative Reporting" (33), which was in effect during the study period. These categories are American Indian or Alaskan Native; Asian or Pacific Islander; black; Hispanic (non-white); and white. Since sample size for American Indian or Alaskan Native and Asian or Pacific Islander was too small to be generalizable, these racial groups were combined within the "other" category in the analyses.

Healthy Life. Traditional measures of health such as mortality and morbidity do not capture important aspects of the quality of life such as social and mental 


\section{0 / Shi et al.}

dysfunction, self-perceived health status, and satisfaction with health. These measures are also difficult to collect in cross-sectional surveys. With the limitations of medical care to improve survival and the potential negative effects of some treatments on quality of life, patients' reports and assessments are increasingly used to assess health status and document the effectiveness of health care (34). Therefore, a single measure that incorporates health-related quality of life and life expectancy provides a more accurate picture of an individual's healthy life. And because increasing the span of healthy life for Americans is one of the three broad goals of Healthy People 2010, this measurement provides baseline information on the nation's racial and ethnic minority populations.

We used a measure of healthy life developed and validated by the National Center for Health Statistics that incorporates both activity limitation and selfperceived health status (35). For activity limitation, each person was classified into one of six categories based on age and ability to perform a major activity: not limited in any way (not limited); not limited in major activity but limited in other activities (limited-other); limited in major activity (limited-major); unable to perform major activity (unable-major); unable to perform instrumental activities of daily living without the help of other persons (limited in IADL); and unable to perform self-care activities of daily living without the help of other persons (limited in ADL). For perceived health, we used a respondent's answer to the question, "Would you say your health in general is excellent, very good, good, fair, or poor?"

The combination of activity limitation and self-perceived health status yielded an integrated measure of healthy life with 30 possible health states ranging from the optimal state of not limited in activity and in excellent health to the lowest state of needing help to perform self-care ADL and being in poor health. The underlying conceptual framework of this measure considers health as a continuum ranging from perfect health to death and including a gradient of different health states within that range. Psychometric techniques and a multi-attribute utility scaling method were used to assign values to each of the 30 possible health states $(35,36)$. Values ranged from 1.0 for persons in perfect health (i.e., with no role limitation and in excellent health) to 0.10 for persons limited in ADL and in poor health. According to these values, if people live one year in excellent health and have no limitation in activity, then they have one full year of healthy life. People limited in $\mathrm{ADL}$ and in poor health have 10 percent of full function for the year.

Usual Source of Care. In the CHC User Survey, only those users who considered $\mathrm{CHCs}$ as their usual source of care were included in the analysis $(\mathrm{n}=1,682)$. Because the NHIS is a population-based rather than user-based survey, the analytic sample was restricted to individuals with a usual source of care and who had made at least one physician visit in the past 12 months $(\mathrm{n}=88,402)$ to maintain comparability with people in the CHC User Survey. Then, individuals whose usual source of care was identified in the NHIS as a CHC and clinics 
$(\mathrm{n}=1,352)$ were excluded to avoid contaminating the comparison. The site of usual source of care for the remaining NHIS sample $(n=87,050)$ was coded as doctor's office or health maintenance organization (HMO); hospital based, which includes outpatient, emergency rooms, and public hospital; and other, which also includes military or Veterans Administration hospitals.

Sociodemographic Covariates. Because racial/ethnic groups differ in sociodemographic characteristics that might be related to health status, these characteristics were included as covariates. They consisted of age, education, family income, employment, marital status, and type of insurance coverage. The continuous measure of age was recoded into three groups $(<18,18-64$, and $65+$ years $)$, because the association of age with health is not linear $(32,33)$. Income was coded as above or below poverty ( $\$ 20,000$ per household). Four categories of insurance were used: public entitlement programs (primarily Medicare and military programs such as CHAMPUS), public welfare programs (primarily Medicaid and other state programs), private insurance (either fee-for-service or managed care programs), and uninsured.

\section{Analysis}

Analyses were performed with SUDAAN, because of the multistage, stratified cluster sampling of the NHIS and CHC User Survey. All analyses accounted for both the design effect and the sampling weights. All estimates presented in the text and tables were weighted to reflect national and $\mathrm{CHC}$ user population totals. We made bivariate comparisons between individuals' race/ethnicity and their experience of healthy life as well as sociodemographic characteristics. Statistical significance was assessed using ANOVA for continuous measures and chi-square tests for categorical measures. Bonferroni's post-hoc means test was used to assess significant disparity in healthy life across racial/ethnic groups. To examine factors associated with variations in healthy life experience, we performed multiple regressions that associate individuals' characteristics (including race/ethnicity) with their healthy life experience (dependent variable). Separate regressions were run on CHC users and NHIS users. For children aged 17 and under, we created dummy categories for certain measures deemed not applicable to them (i.e., education, employment, marital status).

\section{RESULTS}

Bivariate Comparisons: Sociodemographic Characteristics and Healthy Life of Racial/Ethnic Groups

Table 1 compares sociodemographic characteristics across racial and ethnic groups for the 1994 civilian noninstitutionalized population who had a usual 
572 / Shi et al.

Table 1

Racial/ethnic and sociodemographic characteristics, $\mathrm{CHC}$ versus non-CHC users (NHIS users)

\begin{tabular}{|c|c|c|c|c|c|}
\hline & \multicolumn{5}{|c|}{ CHC users (subpopulations, thousands) ${ }^{a}$} \\
\hline & Population & $\begin{array}{c}\text { White } \\
(1,150- \\
744)\end{array}$ & $\begin{array}{c}\text { Black } \\
(1,041- \\
611)\end{array}$ & $\begin{array}{c}\text { Hispanic } \\
(920- \\
481)\end{array}$ & $\begin{array}{c}\text { Other } \\
(215- \\
115)\end{array}$ \\
\hline \multicolumn{6}{|l|}{ Sex } \\
\hline Male & $(1,167,191)$ & 36.25 & 33.53 & 35.32 & 35.47 \\
\hline Female & $(2,158,901)$ & 63.75 & 66.47 & 64.68 & 64.53 \\
\hline \multicolumn{6}{|l|}{ Age } \\
\hline$<18$ & $(1,293,103)^{* * *}$ & 33.25 & 37.42 & 46.46 & 43.60 \\
\hline $18-64$ & $(1,692,293)^{* * *}$ & 51.78 & 51.99 & 49.80 & 45.31 \\
\hline $65+$ & $(340,695)^{* * *}$ & 14.97 & 10.59 & 3.74 & 11.09 \\
\hline \multicolumn{6}{|l|}{ Highest education } \\
\hline No education & $(139,234)^{* * *}$ & 4.00 & 4.57 & 5.35 & 9.34 \\
\hline Primary school & $(1,615,681)^{* * *}$ & 51.29 & 52.67 & 68.89 & 56.32 \\
\hline High school & $(693,093)^{* * *}$ & 24.12 & 30.49 & 16.34 & 23.87 \\
\hline College & $(415,937)^{* * *}$ & 20.59 & 12.27 & 9.43 & 10.46 \\
\hline \multicolumn{6}{|l|}{ Employment } \\
\hline Employed & $(805,723)$ & 41.16 & 43.35 & 41.25 & 31.33 \\
\hline Unemployed & $(1,145,754)$ & 58.84 & 56.65 & 58.75 & 68.67 \\
\hline \multicolumn{6}{|l|}{ Marital status } \\
\hline Married & $(828,733)^{* * *}$ & 42.54 & 22.49 & 43.61 & 40.81 \\
\hline Not married & $(1,455,873)^{* * *}$ & 57.46 & 77.51 & 56.39 & 59.19 \\
\hline \multicolumn{6}{|l|}{ Income } \\
\hline$<20,000$ & $(2,279,013)^{* * *}$ & 65.41 & 80.77 & 77.42 & 78.67 \\
\hline 20,000 & $(786,555)^{* * *}$ & 34.59 & 19.23 & 22.58 & 21.33 \\
\hline \multicolumn{6}{|l|}{ Insurance type } \\
\hline Medicare & $(332,340)^{* * *}$ & 11.05 & 13.62 & 4.76 & 11.83 \\
\hline Medicaid & $(1,164,535)^{* * *}$ & 29.10 & 36.36 & 43.36 & 33.01 \\
\hline Private & $(803,702)^{* * *}$ & 35.11 & 25.27 & 13.36 & 12.68 \\
\hline Uninsured & $(972,415)^{* * *}$ & 24.74 & 24.75 & 38.53 & 42.47 \\
\hline \multicolumn{6}{|l|}{$\begin{array}{l}\text { Site of usual } \\
\text { source of care }\end{array}$} \\
\hline \multicolumn{6}{|l|}{$\begin{array}{l}\text { Doctor's office/ } \\
\text { HMO }\end{array}$} \\
\hline Hospital-based & & & & & \\
\hline Other & & & & & \\
\hline
\end{tabular}

${ }^{a}$ Subpopulations (white, black, Hispanic, other) in parentheses reflect the range (from the highest to the lowest) of the weighted sample size.

$* * * P<.001$. 
Racial/Ethnic Disparities in Healthy Life / 573

\begin{tabular}{|c|c|c|c|c|}
\hline \multicolumn{5}{|c|}{ NHIS users (subpopulations, thousands) ${ }^{a}$} \\
\hline Population & $\begin{array}{c}\text { White } \\
(155,400- \\
74,718)\end{array}$ & $\begin{array}{c}\text { Black } \\
(23,163- \\
9,582)\end{array}$ & $\begin{array}{c}\text { Hispanic } \\
(4,840- \\
1,753)\end{array}$ & $\begin{array}{r}\text { Other } \\
(11,411- \\
4,606)\end{array}$ \\
\hline$(87,894,403)^{* * *}$ & 45.33 & 43.33 & 44.98 & 45.79 \\
\hline$(106,958,833)^{* * *}$ & 54.67 & 56.67 & 55.02 & 54.21 \\
\hline$(55,084,174)^{* * *}$ & 26.32 & 34.25 & 43.45 & 36.20 \\
\hline$(113,068,281)^{* * *}$ & 58.56 & 56.81 & 51.99 & 55.80 \\
\hline$(26,700,781)^{* * *}$ & 15.12 & 8.93 & 4.56 & 8.00 \\
\hline$(26,062,063)^{* * *}$ & 12.28 & 16.40 & 24.62 & 21.05 \\
\hline$(54,103,024)^{* * *}$ & 26.60 & 35.39 & 42.41 & 28.20 \\
\hline$(49,896,948)^{* * *}$ & 26.95 & 24.46 & 16.80 & 18.39 \\
\hline$(62,309,280)^{* * *}$ & 34.17 & 23.75 & 16.18 & 32.37 \\
\hline$(86,743,057)^{* * *}$ & 96.08 & 93.59 & 91.58 & 95.19 \\
\hline$(3,915,729)^{* * *}$ & 3.92 & 6.41 & 8.42 & 4.81 \\
\hline$(90,204,767)^{* * *}$ & 63.29 & 40.93 & 53.07 & 60.34 \\
\hline$(59,012,605)^{* * *}$ & 36.71 & 59.07 & 46.93 & 39.66 \\
\hline$(53,974,200)^{* * *}$ & 24.61 & 50.35 & 51.08 & 30.07 \\
\hline$(134,547,986)^{* * *}$ & 75.39 & 49.65 & 48.92 & 69.93 \\
\hline$(6,547,143)^{* * *}$ & 3.35 & 6.33 & 3.58 & 3.72 \\
\hline$(11,971,548)^{* * *}$ & 4.30 & 18.66 & 23.72 & 11.49 \\
\hline$(142,189,750)^{* * *}$ & 84.48 & 63.60 & 53.67 & 70.81 \\
\hline$(15,636,252) * * *$ & 7.87 & 11.41 & 19.02 & 13.98 \\
\hline$(145,794,144)^{* * *}$ & 78.02 & 63.90 & 57.34 & 60.88 \\
\hline$(6,182,917)^{* * *}$ & 1.98 & 8.64 & 9.68 & 5.63 \\
\hline$(42,876,175)^{* * *}$ & 20.01 & 27.46 & 32.99 & 33.49 \\
\hline
\end{tabular}




\section{4 / Shi et al.}

source of care and at least one physician visit in that year (over 3.3 million CHC users and 194.8 million non-CHC users). The total population size differs across variables owing to different missing and nonapplicable values in the samples. Comparing $\mathrm{CHC}$ with non-CHC users, $\mathrm{CHC}$ users were more likely to be female, younger, unemployed, unmarried, with low income, and uninsured than non-CHC users.

Among $\mathrm{CHC}$ users, Hispanics were significantly younger than other racial groups. Whites had the highest education and Hispanics the lowest. Most blacks (77.51 percent) were unmarried, compared with slight majorities for other racial groups (56.39 to 59.19 percent). Blacks had the highest proportion of users with low income (80.77 percent), followed by "other" groups (78.67 percent), Hispanics (77.42 percent), and whites (65.41 percent). Whites were most likely to have private insurance (35.11 percent). Hispanics and blacks were most likely to have Medicaid. Hispanics and "other" groups had the highest uninsurance (38.53 and 42.47 percent, respectively). These results were consistent with those of other researchers on the $\mathrm{CHC}$ population (27).

Among non-CHC users, Hispanics were younger than other racial groups. Whites had the highest education and Hispanics the lowest. Most blacks (59.07 percent) were unmarried whereas most other racial groups were married (53.07 to 60.34 percent). Whites were most likely to have private insurance (84.48 percent), whereas Hispanics and blacks were more likely to have Medicaid (23.72 and 18.66 percent). Hispanics and "other" groups had the highest uninsurance rates (19.02 and 13.98 percent). Both Hispanics and blacks had a significantly higher proportion of users with low income (51.08 and 50.35 percent) than whites (24.61 percent). Unlike CHC users, Hispanic and black non-CHC users were more likely to be unemployed ( 8.42 and 6.41 percent) than white users (3.92 percent).

Table 2 compares racial differences in healthy life for $\mathrm{CHC}$ and non-CHC users. Non-CHC users were healthier than $\mathrm{CHC}$ users for all racial/ethnic groups. For whites, non-CHC users had 86 percent of full function versus 76 percent for $\mathrm{CHC}$ users; Hispanics, 84 percent versus 80 percent; and blacks, 83 percent versus 77 percent. Among $\mathrm{CHC}$ users, Hispanics experienced significantly healthier life than whites and blacks $(P<.05)$; no significant difference was found between white and black $\mathrm{CHC}$ users. Conversely, among non-CHC users, we see significant healthy life disparities across racial/ethnic groups: whites with significantly better health than both blacks and Hispanics $(P<.05)$, and Hispanics with significantly better health than blacks $(P<.05)$. Although these differences appear small, when multiplied by life expectancy they represent significant differences in years of healthy life. While non-CHC users from racial/ethnic groups experienced greater percentages of full function than $\mathrm{CHC}$ users, black non-CHC users experienced nine fewer years of healthy life than whites. Among 
Table 2

Racial/ethnic disparity in healthy life, CHC versus non-CHC users (NHIS users)

\begin{tabular}{llllll}
\hline & \multicolumn{2}{c}{ CHC users } & & \multicolumn{2}{c}{ NHIS users } \\
\cline { 2 - 3 } \cline { 5 - 6 } & \multicolumn{1}{c}{ Mean } & S.E. & & Mean & S.E. \\
\hline White & $0.7614^{*}$ & 0.0159 & & $0.8622^{*}$ & 0.0014 \\
Black & $0.7658 \#$ & 0.0113 & & $0.8260^{*}$ & 0.0034 \\
Non-white Hispanic & $0.7978^{*}, \#$ & 0.0167 & & $0.8423^{*}$ & 0.0040 \\
Other & 0.7805 & 0.0298 & & $0.8693^{*}$ & 0.0028 \\
\hline
\end{tabular}

* and \# indicate significant differences among racial/ethnic groups (white-non-white Hispanic and black-non-white Hispanic) at $P<.05$ based on Bonferroni's post-hoc means test.

CHC users the gap was almost halved: blacks experienced only five fewer years of healthy life than whites. ${ }^{1}$

Multivariate Comparisons: Race and Sociodemographic

Characteristics Correlated with Healthy Life

Table 3 presents multiple regression results assessing the association of race with healthy life while controlling for sociodemographic correlates of health. Among CHC users, Hispanics experienced significantly healthier life than whites $(P<.05)$; no significant difference was found between blacks and whites. Among non-CHC users, both blacks and Hispanics experienced significantly less healthy life than whites $(P<.01$ and $P<.05$, respectively).

The findings on the association between sociodemographic characteristics and health were comparable for $\mathrm{CHC}$ and non-CHC users. Being female, having better education, high income, and being employed were more likely to be associated with healthier life than being male, having no or low education, low income, and being unemployed. However, the gender, education, and income disparities were far greater among non-CHC users, whereas disparities in employment and marital status were greater among $\mathrm{CHC}$ users. No age disparity in healthy life was found among $\mathrm{CHC}$ users. Among non-CHC users, older people experienced less healthy life than younger people $(P<.01)$. Married $\mathrm{CHC}$ users experienced healthier life

${ }^{1}$ (.8622@76.5 years of life expectancy for whites) - (.8260@69.5 years of life expectancy for blacks) approximately equals 9 years. And (.7614@ 76.5 years of life expectancy for whites) (.7658@69.5 years of life expectancy for blacks) approximately equals 5 years. 
576 / Shi et al.

Table 3

Multiple regressions: correlates of healthy life, $\mathrm{CHC}$ versus non-CHC users (NHIS users) ${ }^{a}$

\begin{tabular}{lrr}
\hline & \multicolumn{1}{c}{ CHC users } & \multicolumn{1}{c}{ NHIS users } \\
\hline Intercept & $0.6067[0.0351]$ & $0.9724[0.0062]$ \\
& $17.2975^{* *}$ & $156.3268^{* *}$ \\
Race & & \\
Black & $0.0150[0.0142]$ & $-0.0195[0.0026]$ \\
Non-white Hispanic & 0.7399 & $-7.0285^{* *}$ \\
& $0.0314[0.0146]$ & $-0.0084[0.0042]$ \\
Other & $2.1465^{*}$ & $-2.0302^{*}$ \\
& $0.0209[0.0250]$ & $0.0039] 0.0026]$ \\
& 0.8373 & 1.5218
\end{tabular}

White (reference)

Sex

Male

$-0.0170[0.0110]$

$-0.0144[0.0012]$

$-1.5403 *$

$-12.4247^{* *}$

Female (reference)

Age

18-64 $0.0013[0.0255]$

0.0507

$65+$

$0.0432[0.0378]$

$<18$ (reference)

Education

No education

-0.0225 [0.0168]

$-1.3388$

High school

0.0546 [0.0165]

$3.2989 * *$

$-0.2005[0.0037]$

$-54.4268^{* *}$

College

0.0753 [0.0184]

$4.0919 * *$

$-0.2181[0.0040]$
$-54.1835^{* *}$

Primary school (reference)

Income

20,000

0.0355 [0.0106]

$3.3484 * *$

0.0116 [0.0018] $6.4797 * *$

0.0537 [0.0028] $19.1954 * *$

0.0856 [0.0028] $30.3086^{* *}$

$<20,000$ (reference) 
Table 3

(Cont'd.)

\begin{tabular}{|c|c|c|}
\hline & $\mathrm{CHC}$ users & NHIS users \\
\hline \multicolumn{3}{|l|}{ Employment } \\
\hline Employed & $\begin{array}{r}0.1630[0.0106] \\
9.7932 * *\end{array}$ & $\begin{array}{r}0.0289[0.0049] \\
5.9448^{* *}\end{array}$ \\
\hline \multicolumn{3}{|c|}{ Unemployed (reference) } \\
\hline \multicolumn{3}{|l|}{ Marital status } \\
\hline Married & $\begin{array}{r}0.0292[0.0090] \\
3.2444 * *\end{array}$ & $\begin{array}{r}-0.0042[0.0018] \\
-2.3556^{*}\end{array}$ \\
\hline \multicolumn{3}{|c|}{ Not married (reference) } \\
\hline \multicolumn{3}{|l|}{ Insurance type } \\
\hline Medicare & $\begin{array}{r}-0.1025[0.0271] \\
-3.7793 * *\end{array}$ & $\begin{array}{r}-0.0891[0.0065] \\
-13.6781^{* *}\end{array}$ \\
\hline Medicaid & $\begin{array}{r}0.0010[0.0111] \\
-0.0926\end{array}$ & $\begin{array}{r}-0.0328[0.0042] \\
-7.7651^{* *}\end{array}$ \\
\hline Uninsured & $\begin{array}{r}0.0208[0.0113] \\
1.8355\end{array}$ & $\begin{array}{r}-0.0165[0.0026] \\
-6.2620^{* *}\end{array}$ \\
\hline \multicolumn{3}{|c|}{ Private (reference) } \\
\hline \multicolumn{3}{|l|}{ Site of usual source } \\
\hline Hospital-based & & $\begin{array}{r}-3.1983^{* *} \\
0.0202[0.0021]\end{array}$ \\
\hline Other & & $9.5415^{* *}$ \\
\hline \multicolumn{3}{|c|}{$\begin{array}{l}\text { Doctor's office/HMO } \\
\text { (reference) }\end{array}$} \\
\hline$R^{2}$ & 0.2855 & 0.2454 \\
\hline
\end{tabular}

${ }^{a}$ For each entry, parameter estimate followed by standard error in brackets; $t$ value below.

$* P<.05 ; * * P<.01$.

than nonmarried $(P<.01)$, yet non-CHC users who were not married experienced healthier life than the married $(P<.05)$. Among non-CHC users, the privately insured experienced healthier life than those with public insurance or without insurance $(P<.01)$, but for CHC users, the uninsured and Medicaid recipients experienced no healthy life disparities compared with the privately insured $(P<.01)$. Non-CHC users whose regular source of care was hospital based 


\section{8 / Shi et al.}

experienced less healthy life than those whose regular source of care was either a doctor's office or an HMO $(P<.01)$.

\section{DISCUSSION}

The results of the study indicate that among users of community health centers, racial/ethnic minorities did not experience worse health than whites as measured by a healthy life indicator. Non-white Hispanics actually experienced healthier life than both whites and blacks. No significant differences were found between white and black $\mathrm{CHC}$ users. In comparison, significant racial/ethnic disparities were found among non-CHC users: whites experienced significantly healthier life than both blacks and non-white Hispanics. These findings persist after controlling for sociodemographic correlates of health. This result suggests that racial/ethnic disparities in health are not simply a straightforward reflection of sociodemographic differences across racial/ethnic groups, and that a more complex relationship underlies the interaction between people of different racial/ethnic backgrounds and the health care system. The absence of racial/ethnic disparities in health among $\mathrm{CHC}$ users might be related to $\mathrm{CHCs}$ ' emphasis on providing ethnically and culturally competent and family-centered care, and their efforts at mobilizing the community to address many of the health and social determinants of healthy life. Other primary care settings, including physicians' offices and HMOs, may not be as well-prepared to serve an increasing number of vulnerable populations who often have a convergence of health and social risks.

Results of this study could be used to monitor the nation's health, measure the progress toward achieving the Healthy People 2010 goal of eliminating health disparities, and evaluate the effectiveness of health systems. Used in combination with life expectancy, the healthy life indicator could yield valuable information on the quality of life of the population. For example, in 1994, the life expectancy at birth for white Americans was 76.5 years and the corresponding number of years of healthy life was 66 years (.8622@76.5). The life expectancy at birth for black Americans was 69.5 years and the corresponding number of years of healthy life was 57 years (.8260@ 69.5). Thus a white American born in 1994 could expect to experience an average of 66 years of healthy life or 86 percent of full function over his or her lifetime, assuming that the mortality and health situations observed in 1994 are maintained. The corresponding expected average of 14 percent dysfunction over the lifetime represents illnesses, both acute and chronic, that occur throughout a life as measured by activity limitation and perceived health (35). In comparison, a black American born in 1994 could expect to experience an average of 57 years of healthy life or 83 percent of full function over his or her lifetime. These percentages and life expectancies could be monitored over time to assess improvements in reducing and eliminating disparities.

Results of this study also have policy implications for strategies on improving the health for the nation's underserved and reducing racial disparities in health. In 
the light of the finding that racial disparities primarily exist in non-CHC settings, with whites enjoying better health status than minorities, efforts need to be directed at these settings to improve health care to racial/ethnic minorities. Because the different racial/ethnic groups often have their own ethnic and cultural backgrounds, medical practitioners need to be sensitive to the various needs of their patients.

It is also important to note that minorities were disproportionately overrepresented in the low income or poor health groups. Blacks and Hispanics were more likely to be of low income and poor health, whites to be of high income and good health. Thus, any adverse association between income and health would disproportionately affect minorities. This is consistent with recent studies showing that the health inequality between socioeconomic groups in the United States has been increasing $(36,37)$. As is clear from many studies $(38,39)$, health inequality is related not only to the health care system but also to the socioeconomic and political aspects of the society. Therefore, improving the traditional concerns of access to care and other public health measures without addressing the socioeconomic and political injustice may not be sufficient to reduce health inequalities in the United States. Likewise, uneven distribution of vulnerable traits across racial/ethnic groups reflects deficiencies in political and economic systems rather than in health care delivery $(40,41)$. The fulfillment of the Healthy People 2010 goal of eliminating racial disparities in health would require concerted efforts to raise the socioeconomic status of racial/ethnic minorities in addition to improving their access to and quality of care (42).

The study has several limitations. Only three generally recognized racial/ ethnic groups were studied, but the U.S. population is extremely heterogeneous. Studies involving multicultural populations need to be mindful of the complexities involved so as to avoid basing generalizations on broad racial/ethnic categorical definitions. Moreover, measurements of race in research are actually measures of skin color and do not capture culture, biology, values, or behavior (43). Race is often used as a proxy for the influences of biological, cultural, socioeconomic, and political factors and exposure to racism (44). All these components are interrelated and may interact with each other (45). Another limitation is that, given the cross-sectional nature of the data, we cannot draw conclusions about causal directions of the relationships studied. For example, we cannot ascertain that it is CHCs that caused the elimination of racial/ethnic disparities in health or, for that matter, that the non-CHC sites contributed to such disparities. Longitudinal studies, with data collected over time on the same individuals, are needed to establish causality; no such datasets are currently available. Another potential limitation is that the two samples might be significantly different in sociodemographics so that they reflect two very different samples of income groups. With insufficient numbers of individuals of higher income status using CHCs, it is not possible to eliminate income status as a predictor of health status in the CHC sample. Nevertheless, the study does demonstrate that while racial/ethnic 
580 / Shi et al.

disparities in health persist nationally, these disparities do not exist within CHCs, safety-net providers with an explicit mission to serve vulnerable populations. Future research should explore the mechanisms used by CHCs to reduce or eliminate these disparities in health and health care. This information can then be promulgated to other providers who are faced with a growing number of vulnerable populations including racial and ethnic minorities.

Acknowledgments - This study was supported by the Johns Hopkins Primary Care Policy Center for the Underserved and the Bureau of Primary Health Care, Health Resources and Services Administration.

\section{REFERENCES}

1. Sorlie, P., et al. Black-white mortality differences by family income. Lancet 340 : 346-350, 1992.

2. Anderson, R. M., Giachello, A. L., and Aday, L. A. Access of Hispanics to health care and cuts in services: A state-of-the-art overview. Public Health Rep. 101: 238-252, 1986.

3. Whittle, J., et al. Racial differences in the use of invasive cardiovascular procedures in the Department of Veterans Affairs medical system. N. Engl. J. Med. 329: 621-627, 1993.

4. Lieu, T. A., Newacheck, P. W., and McManus, J. Race, ethnicity, and access to ambulatory care among US adolescents. Am. J. Public Health 83: 960-965, 1993.

5. Escarce, J. J., et al. Racial differences in the elderly use of medical procedures and diagnostic tests. Am. J. Public Health 83: 939-941, 1993.

6. Woolhandler, S. Medical care and mortality: Racial differences in preventable deaths. Int. J. Health Serv. 15: 1-11, 1985.

7. Manton, K. G. Health differentials between blacks and whites: Recent trends in mortality and morbidity. Milbank Q. 65(Suppl.1): 129-199, 1987.

8. Cornelius, L. J., and Andersen, R. M. Black-white differences in health status: Methods or substance. Milbank Q. 65(Suppl.1): 72-99, 1987.

9. Carlisle, D. M., Leake, B. D., and Shapiro, M. F. Racial and ethnic differences in the use of invasive cardiac procedures among cardiac patients in Los Angeles county, 1986 through 1988. Am. J. Public Health 85: 352-356, 1995.

10. Zoratti, F. M., et al. Health service use by African Americans and Caucasians with asthma in a managed care setting. Am. J. Resp. Crit. Care Med. 158: 371-377, 1998.

11. Fichtenbaum, R., and Gyimah-Brempong, K. The effects of race on the use of physician's services. Int. J. Health Serv. 27: 139-156, 1997.

12. Blendon, R. J., et al. Access to medical care for black and white Americans. JAMA 261: 278-281, 1989.

13. Wenneker, M. B., and Epstein, A. M. Racial inequalities in the use of procedures for patients with ischemic heart disease in Massachusetts. JAMA 261: 253-257, 1989.

14. Nickens, H. W. The role of race/ethnic and social class in minority health status. Health Serv. Res. 30: 151-162, 1995.

15. Blustein, J., and Weitzman, B. C. Access to hospitals with high-technology cardiac services: How is race important? Am. J. Public Health 85: 345-351, 1995. 
16. Nickens, H. W. Race/ethnicity as a factor in health and health care. Health Serv. Res. 30: 151-162, 1995.

17. U.S. Department of Health and Human Services. Healthy People 2010 Objectives: Draft for Public Comment. U.S. Government Printing Office, Washington, D.C., September 15, 1998.

18. Aday, L. A., and Anderson, R. M. The national profile of access to medical care: Where do we stand? Am. J. Public Health 74: 1331, 1984.

19. Hayward, R. A., et al. Regular source of ambulatory care and access to health services. Am. J. Public Health 81: 434-438, 1990.

20. Lambrew, J. M., et al. The effects of having a regular doctor on access to primary care. Med. Care 34: 138-151, 1996.

21. Barrett, R. J., et al. Endometrial cancer: Stage at diagnosis and associated factors in black and white patients. Am. J. Obstet. Gynecol. 173: 414-423, 1995.

22. Shea, S., et al. Correlates of nonadherence to hypertension treatment in an inner-city minority population. Am. J. Public Health 82: 1607-1612, 1992.

23. Cornelius, L. J. Access to medical care for black Americans with an episode of illness. J. Natl. Med. Assoc. 83: 617-626, 1991.

24. Lurie, N., et al. Termination from Medi-Cal: Does it affect health? JAMA 252: 2413-2417, 1984.

25. Institute of Medicine. Primary Care: America's Health in a New Era. National Academy Press, Washington, D.C., 1996.

26. Forrest, C. B., and Whelan, E. M. Primary care safety-net providers in the United States: A comparison of community health centers, hospital outpatient departments, and physicians' offices. Unpublished paper.

27. Politzer, R., et al. Inequality in America: Reducing and eliminating health status disparities. Unpublished paper.

28. Regan, J., Lefkowitz, B., and Gaston, M. Cancer screening among community health center women: Eliminating the gaps. J. Ambulatory Care Manage. 22: 45-52, 1999.

29. U.S. General Accounting Office. Community Health Centers: Challenges in Transitioning to Prepaid Managed Care. GAO/HEHS 95-138. Washington, D.C., April 1995.

30. U.S. General Accounting Office. Community Health Centers: Adapting to Changing Health Care Environment Key to Continued Success. GAO/HEHS 00-39. Washington, D.C., March 2000.

31. Carcagno, G. J., et al. Community Health Center User and Visit Study Survey Methodology Report. Mathematica Policy Research, Princeton, N.J., August 29, 1997.

32. Jones, C. P., LaVeist, T. A., and Lillie-Blanton, M. L. 'Race' in the epidemiologic literature: An examination, 1921-1990. Am. J. Epidemiol. 134: 1079-1084, 1991.

33. Office of Management and Budget. Director no. 15: Race and ethnic standards for federal statistics and administrative reporting. In Statistical Policy Handbook, 37-38. Office of Federal Statistics and Policy and Standards, U.S. Department of Commerce, Washington, D.C., 1978.

34. Reiser, S. J. The era of the patient: Using the experience of illness in shaping the missions of health care. JAMA 269: 1012-1017, 1993.

35. Erickson, P., Wilson, R., and Shannon, I. Years of healthy life. Statistical Notes 7: $1-14,1995$. 
582 / Shi et al.

36. Pappas, G., Queen, S., and Hadden, W. The increasing disparity in mortality between socioeconomic groups in the United States, 1960 and 1986. N. Engl. J. Med. 329(2): 103-109, 1993.

37. Schalick, L. M., Hadden, W. C., and Pamuk, E. The widening gap in death rates among income groups in the United States from 1967 to 1986. Int. J. Health Serv. 30(1): 13-26, 2000.

38. O'Keefe, E. Equity, democracy and globalization. Crit. Public Health 10(2): 167-177, 2000.

39. Whiteis, D. G. Poverty, policy, and pathogenesis: Economic justice and public health in the U.S. Crit. Public Health 10(2): 257-271, 2000.

40. Williams, D. R., and Rucker, T. D. Understanding and addressing racial disparities in health care. Health Care Financ. Rev. 21(4): 75-90, 2000.

41. Fiscella, K., et al. Inequality in quality: Addressing socioeconomic, racial, and ethnic disparities in health care. JAMA 283(19): 2579-2584, 2000.

42. Moss, N. Socioeconomic disparities in health in the US: An agenda for action. Soc. Sci. Med. 51: 1627-1638, 2000.

43. LaVeist, T. A. Beyond dummy variables and sample selection: What health services researchers ought to know about race as a variable. Health Serv. Res. 29: 1-16, 1994.

44. Anderson, N. B., et al. Macrosocial and environmental influences on minority health. Health Psychol. 14: 601-612, 1995.

45. Schulman, K. A., et al. The roles of race and socioeconomic factors in health services research. Health Serv. Res. 30: 179-195, 1995.

Direct reprint requests to:

Dr. Leiyu Shi

Department of Health Policy and Management

Johns Hopkins School of Hygiene and Public Health

624 North Broadway, Room 409

Baltimore, MD 21205-1996 